\title{
A pilot investigation into the potential of mineral magnetic measurements as a proxy for urban roadside particulate pollution
}

\author{
C. A. Booth ${ }^{1}$, C. M. Winspear ${ }^{2}$, M. A. Fullen ${ }^{2}$, A. T. Worsley ${ }^{3}$, \\ A. L. Power ${ }^{3}$ \& V. J. Holden ${ }^{3}$ \\ ${ }^{1} S E B E$, University of Wolverhampton, $U K$ \\ ${ }^{2} S A S$, University of Wolverhampton, $U K$ \\ ${ }^{3} N G A S$, Edge Hill University, UK
}

\begin{abstract}
The use of mineral magnetic concentration parameters $\left(\chi_{\mathrm{LF}}, \chi_{\mathrm{ARM}}\right.$ and SIRM) as a potential particle size proxy for urban street dust collected from Southport (Merseyside, UK) is explored. Correlation analyses between each magnetic parameter and traditional particle size classes (i.e. sand, silt and clay) and respiratory health related size classes (i.e. $\mathrm{PM}_{10}, \mathrm{PM}_{2.5}$ and $\mathrm{PM}_{1.0}$ ) are reported. Significant relationships $(\mathrm{p}<0.001 ; \mathrm{n}=50)$ exist between sand, silt and clay content with at least one or all of the magnetic concentration parameters. This is also the same for each $\mathrm{PM}_{10}, \mathrm{PM}_{2.5}$ and $\mathrm{PM}_{1.0}$ sizes. Of the three magnetic parameters, $\chi_{\mathrm{LF}}$ displays the strongest correlation values $(\mathrm{r}=0.701, \mathrm{P}<0.001$, $\mathrm{n}=50)$ and is the most significant parameter, which is consistent with all class sizes of each approach. In doing so, these associations indicate mineral magnetic measurements have considerable potential as a particle size proxy for determining urban roadside particulate matter concentrations. Given the speed, low-cost and sensitivity of the measurements, this suggests magnetic techniques could potentially be used as an alternative and/or complementary exploratory technology for pilot particulate pollution investigations. Furthermore, in certain instances, it could be useful for examining linkages between respiratory health and particulate pollution and vehicle emissions.

Keywords: environmental magnetism, particle size, urban street dust, built environment, epidemiology, public health.
\end{abstract}




\section{Introduction}

Urban pollution, particularly particulate matter (PM), continues to be intensively studied because dust particles can exert a potentially harmful influence on public health, especially those susceptible to respiratory illness [1, 2]. It is customary to analyse particulates of two size fractions; the coarse fraction $\mathrm{PM}_{10}\left(d_{\mathrm{a}} \leq 10 \mu \mathrm{m}\right)$ and fine fraction $\mathrm{PM}_{2.5}\left(d_{\mathrm{a}} \leq 2.5 \mu \mathrm{m}\right)$. More recently, the adopted changeover point between coarse and fine particles occurs at $\mathrm{PM}_{1.0}\left(d_{\mathrm{a}} \leq 1.0 \mu \mathrm{m}\right)$. The success or failure of the respiratory defence systems partly depends upon the size of the particulates inhaled and the depth of their penetration into the respiratory tract. A recent assessment by the 'Expert Panel on Air Quality Standards' [3] concluded that both coarse and fine fractions represent health risks, although the disease outcomes may differ for the two size fractions [4].

Since 1997, UK local authorities have been reviewing and assessing air quality in their area, to work towards meeting the national air quality objectives. There are over 1500 monitoring sites across the UK, which monitor air quality (monitoring $\mathrm{PM}_{10}$ concentrations, amongst those of several other pollutant measurements). In 2003 the UK Government set lower limits for fine particle concentrations, which need to be reached by 2010. Currently, the main source of airborne fine particulates in the UK is road traffic emissions. However, it is estimated, by 2010, that road transport emissions of fine particles will fall by two-thirds of those a decade ago [5]. Moreover, the European Commission has proposed that the legislation on particulate matter should be supplemented by setting a limit value of $35 \mu \mathrm{g} / \mathrm{m}^{3}$ for $\mathrm{PM}_{2.5}$ particles and an interim reduction target of $20 \%$ to be attained between 2010 and 2020 [6]. Assessment of the extent and severity of urban dust concentrations requires thorough investigation before Air Quality Management Plans and remediation can be instigated, which means that there is scope for new PM monitoring technologies.

It is, therefore, timely for innovative PM technologies to be considered as an alternative, or in tandem, to those already employed to determine $\mathrm{PM}_{2.5}$ and $\mathrm{PM}_{10}$ concentrations. Moreover, ideally, they need to be rapid, reliable and inexpensive. However, to assess the suitability of any analytical technique as an efficient particle size proxy it is necessary that the nature of the relationship between the proposed parameters and particle size follow a predictable pattern. Many studies have previously explored relationships between mineral magnetic measurements and the physico-chemical properties of soils, sediments and dusts. Based on these investigations, from a host of environmental settings (e.g. soils, deserts, glacial, lakes, coastal and marine), magnetic measurements have previously been identified as a suitable proxy for geochemical, radioactivity, organic matter content and particle size data.

Two hypotheses are tested here. Firstly, the extent to which particular magnetic concentration parameters can be used as a particle size proxy for urban street dust and, secondly, whether theses data associations follow the predictable trends of other environmental studies [7-9]. 


\section{Case study}

The town of Southport (2216 hectares), part of Sefton Metropolitan Borough Council (Merseyside, UK), located between the cities of Liverpool and Preston, is a coastal resort in NW England (Figure 1). Founded in 1798, visitors have been coming to Southport's stunning expanse of sandy beaches $(\sim 35 \mathrm{~km}$ long) and seaside attractions for over two centuries and these are still immensely important to the town today. However, much of the town's major growth was in the $19^{\text {th }}$ Century, when it gained a reputation for being a refined seaside resort, and this is still reflected in much of the town's design

The town centre has wide streets, lined with shops, banks and civic buildings (Lord Street, Chapel Street, Eastbank Street, London Street), which include a tree-lined boulevard ( $\sim 2 \mathrm{~km}$ long) decorated with imposing three and four storey Victorian (1837-1901) buildings. Nowadays, these ornate buildings, fronted with glass awnings, serve as exclusive shopping outlets. Lord Street is where the town started, from a valley in the sand dunes, and it is this that defined the geography of early Southport and its road network [10].

Surrounding the town centre is a suburb of Victorian and Edwardian detached and semi-detached houses, which, further away, become progressively grander (with turrets and chateau-like towers) until reaching the modern housing estates clustering the town's limits. Together, these are home to a population of 91,404 (2001 Census) [11].

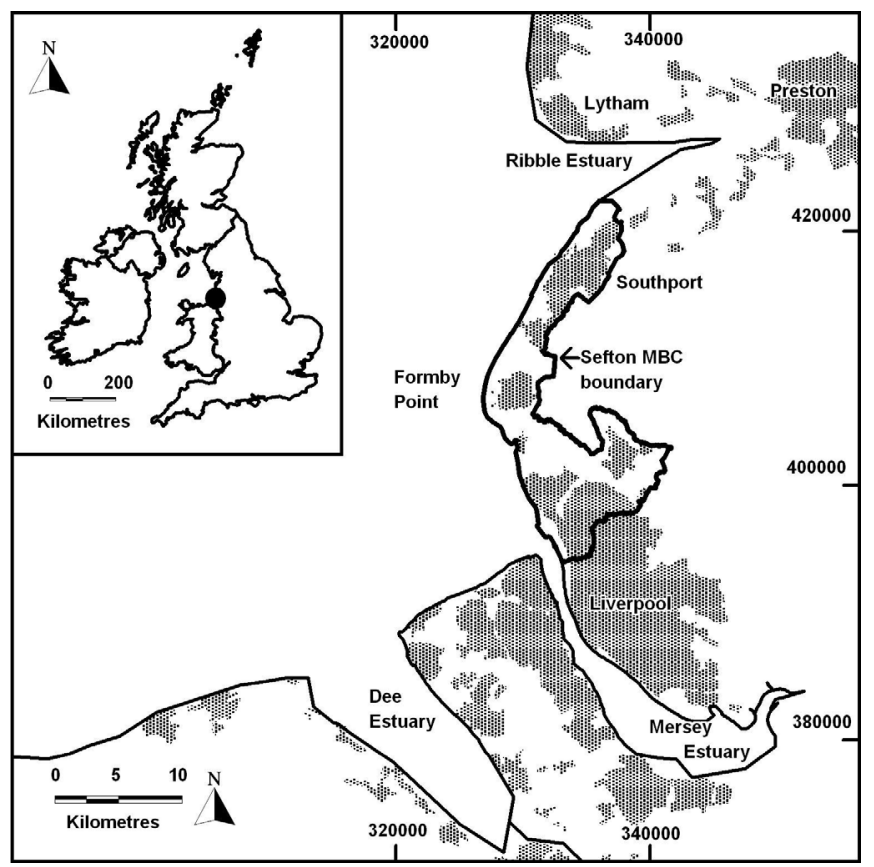

Figure 1: $\quad$ Location map of Southport and its position within Sefton MBC. 


\subsection{The context for focussing on Southport town centre}

The strategy for Transportation in Southport (TRANSIS 2010) was published in 1999 and, subsequently, in 2000, incorporated into the Merseyside Local Transport Plan (Merseyside LTP). The Merseyside LTP identified a 10-year transportation strategy for Merseyside, with a five-year programme of investment focused on strategy delivery. The aim is to develop a fully integrated and sustainable transport network for Merseyside, which supports economic, social and environmental regeneration and ensures good access for all the community. The Merseyside LTP transport investment programme in Sefton includes a variety of schemes and initiatives. Sefton has benefited from over $£ 35.4 \mathrm{~m}$ (provided by central Government) of investment in transport schemes, namely the construction of the Marine Way Bridge $(£ 7.7 \mathrm{~m})$; improvements to Nevill Street $(£ 1.5 \mathrm{~m})$; improvements to Eastbank Street $(£ 0.85 \mathrm{~m})$; and the pedestrianization of Chapel Street ( $£ 4 \mathrm{~m})$ (Figure 2$)$, amongst other work within the Borough [12].

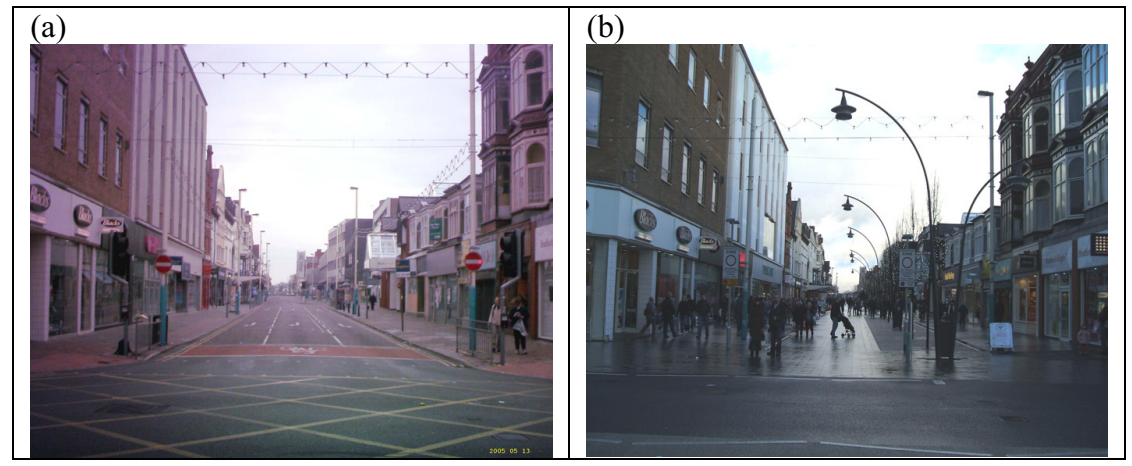

Figure 2: Chapel Street (a) prior to redevelopment (May 2005) and (b) close to finishing the redevelopment (January 2007).

The TRANSIS 2010 strategy aims to support and contribute to Southport's continuing success in retail, tourism, leisure and business. This means retaining good access to the town, easing circulation within the town and enhancing the environment, both in the town centre and surrounding residential areas. The strategy is based around three key themes: economic regeneration; increased access and mobility and environmental improvement [12].

\subsection{Pedestrianization of Chapel Street}

Chapel Street is one of the main shopping areas in Southport and is also the main arrival point for visitors travelling by public transport. As such, Chapel Street is being converted from a street dominated by busy traffic to create a safe, attractive and fully pedestrianized area for shoppers and visitors, with trees, seating, improved street-lighting, CCTV security cameras and ample space. The Chapel Street scheme is viewed as an essential element in the regeneration 
of Southport and in raising the profile of the town as a vibrant and successful commercial, retail and leisure destination and being a 'Classic Resort' [12].

The closure of Chapel Street will result in traffic being transferred onto other routes in and around the town centre. Therefore, specialist consultants were employed to conduct an impact assessment of this on the town centre. This showed that projected traffic displaced as a result of the pedestrianization could be accommodated within the existing town centre highway network [12].

\section{Materials and methods}

Samples used in this study form the first stage of an on-going investigation by the authors. Prior to redevelopment work starting, street dust samples were collected from all town centre roads and the sites georeferenced (May 2005). The redevelopments are now scheduled to finish early 2007. After which (May 2008), it is proposed that the same sites will be re-sampled. Subsequently, spatial variations in the magneto-chemical properties of the particulate pollution will be compared with those of the first stage, so as to identify how changes in traffic direction and flow relate to any changes in spatial particulate pollution patterns.

\subsection{Sample collection and preparation}

Street dust was collected from the pavements (sidewalks) of town centre roads. Typically, 10-50 g dust samples were collected (from $\sim 1 \mathrm{~m}^{2}$ ) by brushing with a small hand-held fine-bristle brush. Dust was then transferred to clean, pre-labelled, self-seal, airtight plastic bags. In the laboratory, samples were visibly screened to remove macroscopic traces of hair, animal and plant matter.

\subsection{Mineral magnetic measurements}

All samples were subjected to the same preparation and analysis procedure. Samples were dried at room temperature $\left(<40^{\circ} \mathrm{C}\right)$, weighed, packed into $10 \mathrm{ml}$ plastic pots and immobilized with clean sponge foam and tape prior to analysis. Initial, low-field, mass-specific, magnetic susceptibility $(\chi)$ was measured using a Bartington (Oxford, England) MS2 susceptibility meter. By using a MS2B sensor, low frequency susceptibility was measured $\left(\chi_{\mathrm{LF}}\right)$. Anhysteretic Remanence Magnetisation (ARM) was induced with a peak alternating field of $100 \mathrm{mT}$ and small steady biasing field of $0.04 \mathrm{mT}$ using a Molspin (Newcastleupon-Tyne, England) A.F. demagnetiser. The resultant remanence created within the samples was measured using a Molspin 1A magnetometer and the values converted to give the mass specific susceptibility of ARM $\left(\chi_{\text {ARM }}\right)$. The samples were then demagnetized to remove the induced ARM and exposed to a series of successively larger field sizes up to a maximum 'saturation' field of $1000 \mathrm{mT}$, followed by a series of successively larger fields in the opposite direction (backfields), generated by two Molspin pulse magnetisers (0-100 and 0-1000 mT). After each 'forward' and 'reverse' field, sample isothermal remanent magnetisation (IRM) was measured using the magnetometer. 


\subsection{Laser diffraction measurements}

All samples were subjected to the same textural preparation and analysis procedure, using sieving (2000 $\mu \mathrm{m}$ aperture) followed by laser diffraction analysis. Low Angle Laser Light Scattering (LALLS), using a Malvern (Malvern, England) Mastersizer Long-bed X with a MSX17 sample presentation unit, enabled rapid measurement of particle sizes within the $0.1-2000 \mu \mathrm{m}$ range. Macroscopic traces of organic matter were removed from representative subsamples before being dampened by the dropwise addition of a standard chemical solution (40 g/l solution of sodium hexametaphosphate $\left(\left(\mathrm{NaPO}_{3}\right)_{6}\right)$ in distilled water) to help disperse aggregates. To ensure complete disaggregation, each slurry was then subjected to ultrasonic dispersion in a Malvern MSX17 sample presentation unit. For greater precision, the mean of five replicate analyses was measured with a mixed refractive indices presentation setting. A standard range of textural parameters was calculated, including the percentage of sand, silt and clay class sizes and their sub-intervals. The Malvern instrumentation was regularly calibrated using latex beads of known size.

\section{Results}

Particle size data $(\mathrm{n}=50)$ indicates samples are dominated by sand $(\sim 65 \%)$, silt $(\sim 32 \%)$ and clay $(\sim 2 \%)$, in respective orders (Table 1). Given the coastal setting of the town and visual inspection of quartz-dominant grains in the samples, it is presumed that most sand-size material is wind-blown and derived from the local foreshore.

Table 1: $\quad$ Summary particle size properties of urban roadside particulates (a) traditional sediment size fractions and (b) respiratory healthrelated size fractions $(\mathrm{n}=50$ samples).

\begin{tabular}{|l|c|c|c|c|}
\hline & $\begin{array}{c}\text { Mean } \\
(\%)\end{array}$ & $\begin{array}{c}\text { Maximum } \\
(\%)\end{array}$ & $\begin{array}{c}\text { Minimum } \\
(\%)\end{array}$ & $\begin{array}{c}\text { Standard } \\
\text { Deviation }\end{array}$ \\
\hline Sand $(63-2000 \mu \mathrm{m})$ & 65.14 & 75.62 & 42.11 & 5.34 \\
\hline Silt $(2-63 \mu \mathrm{m})$ & 32.73 & 53.77 & 22.57 & 4.94 \\
\hline Clay $(<2 \mu \mathrm{m})$ & 2.13 & 4.12 & 1.39 & 0.49 \\
\hline
\end{tabular}

\begin{tabular}{|l|c|c|c|c|}
\hline & $\begin{array}{c}\text { Mean } \\
(\%)\end{array}$ & $\begin{array}{c}\text { Maximum } \\
(\%)\end{array}$ & $\begin{array}{c}\text { Minimum } \\
(\%)\end{array}$ & $\begin{array}{c}\text { Standard } \\
\text { Deviation }\end{array}$ \\
\hline$<\mathrm{PM}_{10}$ & 9.10 & 15.56 & 6.33 & 1.81 \\
\hline$<\mathrm{PM}_{2.5}$ & 2.64 & 4.90 & 1.77 & 0.57 \\
\hline$<\mathrm{PM}_{1.0}$ & 0.85 & 2.44 & 0.51 & 0.33 \\
\hline
\end{tabular}

From a respiratory-health perspective, $\mathrm{PM}_{10}$ grains represent $\sim 9 \%, \mathrm{PM}_{2.5} \sim 3 \%$ and $\mathrm{PM}_{1.0} \sim 1 \%$ of the dusts at pavement level. Since the town has no heavy 
industrial activity, it is presumed that the most local anthropogenic PM pollution is derived from vehicle emissions. However, this is probably not exclusive because, depending on wind direction, some PM pollution may be derived from the regional cities of Liverpool and/or Preston.

Once suspended, particles $<10 \mu \mathrm{m}$ in diameter are able to remain airborne for hours or days and, in some cases, even weeks (Harrison, 2004). Therefore, the presence of PM of these sizes on pavement surfaces indicates either the dusts have not been disturbed recently or they have only just settled-out. That said, since the town centre pavements normally receive frequent and heavy foottraffic, it is assumed the time of sampling $(0500-0800)$ and the weather conditions (warm, dry and still) have permitted sizeable PM accumulations.

Table 2 summarizes the mineral magnetic characteristics. $\chi_{\mathrm{LF}}$ is roughly proportional to the concentration of ferrimagnetic minerals within the sample, although in materials with little or no ferrimagnetic component and a relatively large antiferromagnetic component, the latter may dominate the signal. $\chi_{\text {ARM }}$ is particularly sensitive to the concentration of magnetic grains of stable single domain size, e.g. $\sim 0.03-0.06 \mu \mathrm{m}$. SIRM is related to concentrations of all remanence-carrying minerals in the sample, but is also dependent upon the assemblage of mineral types and their magnetic grain size. These data indicate the samples contain moderate to high magnetic concentrations. Yet, compared with previous urban magneto-dust studies, the mean values are similar to those of Liverpool $\left(23.7 \times 10^{-7} \mathrm{~m}^{3} \mathrm{~kg}^{-1}\right)$ [13] and Shanghai $\left(29.9 \times 10^{-7} \mathrm{~m}^{3} \mathrm{~kg}^{-1}\right)$ [14].

Table 2: Summary mineral magnetic properties of urban roadside particulates $(\mathrm{n}=50$ samples $)$.

\begin{tabular}{|l|c|c|c|c|c|}
\hline & Units & Mean & $\begin{array}{c}\text { Maximu } \\
\mathrm{m}\end{array}$ & Minimum & $\begin{array}{c}\text { Standard } \\
\text { Deviation }\end{array}$ \\
\hline$\chi_{\mathrm{LF}}$ & $10^{-7} \mathrm{~m}^{3} \mathrm{~kg}^{-1}$ & 27.95 & 62.80 & 14.33 & 9.91 \\
\hline$\chi_{\mathrm{ARM}}$ & $10^{-7} \mathrm{~m}^{3} \mathrm{~kg}^{-1}$ & 0.30 & 0.65 & 0.00 & 0.17 \\
\hline SIRM & $10^{-5} \mathrm{Am}^{2} \mathrm{~kg}^{-1}$ & 2345.41 & 6291.61 & 1189.11 & 946.26 \\
\hline
\end{tabular}

Table 3 shows the Pearson's correlation coefficient values $(r)$ between the mineral magnetic concentration parameters and particle size parameters, grouped according to traditional sediment size fractions and respiratory health-related size fractions. Significant relationships $(\mathrm{P}<0.001 ; \mathrm{n}=50)$ exist between sand, silt and clay content with at least one or all of the magnetic concentration parameters. This is also the same for each $\mathrm{PM}_{10}, \mathrm{PM}_{2.5}$ and $\mathrm{PM}_{1.0}$ sizes. However, of the three magnetic parameters, $\chi_{\mathrm{LF}}$ has the strongest and most significant correlation values and, furthermore, is consistently significant $(\mathrm{P}<0.001)$ with all class sizes from both groups. $\chi_{\text {ARM }}$ has mixed significance levels $(\mathrm{P}<0.01$ and $\mathrm{P}$ $<0.05$ ) for both groups, yet has no association with $\mathrm{PM}_{10}$. In contrast with both these parameters, SIRM only has significant $(\mathrm{P}<0.05)$ kinships with the very finest fractions, such as $<1.0 \mu \mathrm{m},<2.0 \mu \mathrm{m}$ and $2.5 \mu \mathrm{m}$, and not with fractions $\geq 10 \mu \mathrm{m}$. Therefore, this indicates all the magnetic concentration parameters 
could be used as a particle size proxy, particularly if the kinship is required with particles $<\mathrm{PM}_{2.5}$, but it also indicates that $\chi_{\mathrm{LF}}$ could be used if the kinship is required with a wider spectrum of particle sizes.

Table 3: Pearson's correlation coefficients (r) between mineral magnetic concentration and particle size parameters for urban roadside particulates (a) traditional sediment size fractions and (b) respiratory health-related size fractions $(\mathrm{n}=50$ samples).

\begin{tabular}{|l|c|c|c|}
\hline (a) & $\begin{array}{c}\text { Clay } \\
<2 \mu \mathrm{m}\end{array}$ & $\begin{array}{c}\text { Silt } \\
2-63 \mu \mathrm{m}\end{array}$ & $\begin{array}{c}\text { Sand } \\
63-2000 \mu \mathrm{m}\end{array}$ \\
\hline$\chi_{\text {LF }}$ & $0.701 * * *$ & $0.645^{* * *}$ & $-0.667 * * *$ \\
\hline$\chi_{\text {ARM }}$ & $0.330^{*}$ & $0.372 * *$ & $-0.378^{* *}$ \\
\hline SIRM & $0.338^{*}$ & 0.172 & 0.192 \\
\hline
\end{tabular}

\begin{tabular}{|l|c|c|c|}
\hline$(\mathrm{b})$ & $<\mathrm{PM}_{1.0}$ & $<\mathrm{PM}_{2.5}$ & $<\mathrm{PM}_{10}$ \\
\hline$\chi_{\mathrm{LF}}$ & $0.659 * * *$ & $0.705^{* * *}$ & $0.687 * * *$ \\
\hline$\chi_{\mathrm{ARM}}$ & $0.413^{* *}$ & $0.298^{*}$ & 0.134 \\
\hline SIRM & $0.315^{*}$ & $0.325^{*}$ & 0.236 \\
\hline
\end{tabular}

Note: Significance levels: $\mathrm{P}<0.05=* ; \mathrm{P}<0.01=* * ; \mathrm{P}<0.001=* * *$

\section{Discussion}

Previous magnetic studies have noted significant correlations between $\chi_{\mathrm{LF}}, \chi_{\mathrm{ARM}}$, SIRM and particle size. To date, Oldfield et al. [15] has identified that anhysteretic remanent magnetisation (ARM) measurements can be used to reflect the concentration of fine-grained magnetite $(<0.1 \mu \mathrm{m})$ in the clay fraction and low-frequency magnetic susceptibility $\left(\chi_{\mathrm{LF}}\right)$ measurements can be used to infer the presence of coarser multi-domain magnetite $(>1.0 \mu \mathrm{m})$ in sands and coarse silts. Clifton et al. [8] found $\chi_{\mathrm{LF}}$ was strongly associated with sands and medium silts, susceptibility of ARM $\left(\chi_{\text {ARM }}\right)$ was strongly associated with clay and fine silts, and saturated isothermal remanent magnetisation (SIRM) was strongly associated with very fine to medium silts. Zhang et al. [16] suggested that both percentage frequency-dependent magnetic susceptibility $\left(\chi_{\mathrm{FD} \%}\right)$ and $\chi_{\mathrm{ARM}}$ can be used as a proxy for clay content. However, more recently, Booth et al. [9] suggested $\chi_{\text {LF }}, \chi_{\text {ARM }}$ and SIRM have potential as a particle size proxy for particular sedimentary environments, but highlight the importance of fully determining the nature of the relationship between sediment particle size and magnetic properties before applying mineral magnetic data as a size proxy.

These studies illustrated sand correlated negatively with $\chi_{\mathrm{LF}}(\mathrm{r}=-0.94), \chi_{\mathrm{ARM}}$ $(\mathrm{r}=-0.96)$ and SIRM $(\mathrm{r}=-0.91)$; silt correlated positively with $\chi_{\mathrm{LF}}(\mathrm{r}=0.96)$, $\chi_{\mathrm{ARM}}(\mathrm{r}=0.96)$ and SIRM $(\mathrm{r}=0.96)$; and clay correlated positively with $\chi_{\mathrm{LF}}$ 
$(\mathrm{r}=0.82), \chi_{\mathrm{ARM}}(\mathrm{r}=0.94)$ and SIRM $(\mathrm{r}=0.81)$. When data presented here are compared to these earlier investigations, it is apparent that the trends observed are similar to previous studies (e.g. sand and $\chi_{\mathrm{ARM}}(\mathrm{r}=-0.38)$, silt and $\chi_{\mathrm{LF}}(\mathrm{r}=$ $0.65)$, clay and SIRM $(\mathrm{r}=0.34)$ ). The magneto-associations with each of the traditional sediment class sizes highlights the potential use of mineral magnetic data as a means of normalizing compositional analytical data (i.e. geochemical) for particle size effects.

The significant correlations between the magnetic parameters and the respiratory-health related size classes is perhaps of greater importance, because this highlights the technique as a possible alternative PM monitoring tool, which could be linked to both health and pollution studies. Given the combination of low-cost and sensitivity of the method, it can be argued that mineral magnetic measurements have considerable potential to act as a reliable particle size proxy. The method is also rapid; bulk samples require little preparation and individual measurements of magnetic susceptibility $\left(\chi_{\mathrm{LF}}\right)$ can be made in $\sim 1$ minute, in either a laboratory or field setting. Therefore, it is feasible that mineral magnetic measurements could be a dependable and rapid exploratory technology for pilot urban roadside PM investigations.

\section{Conclusions}

Analyses indicate each of the magnetic concentration parameters could be reliably employed as a suitable particle size proxy for urban street dust. Of the three magnetic parameters, $\chi_{\mathrm{LF}}$ has the strongest and most significant correlation values and, furthermore, is consistently significant $(\mathrm{P}<0.001)$ with all class sizes. Moreover, theses data associations follow the predictable trends of other environmental studies. Therefore, given the speed, low-cost and sensitivity of the measurements, this suggests magnetic techniques could be used as a rapid alternative exploratory technology for pilot particulate pollution investigations.

\section{Acknowledgements}

This research forms part of the Early Researcher Award Scheme (ERAS) funded by The University of Wolverhampton, for which the leader author expresses his gratitude. All authors thank the School of Applied Sciences at The University of Wolverhampton for unlimited access to analytical facilities. Thanks are also extended to Graham Lymbery and Paul Wisse (Sefton MBC) for producing the location map.

\section{References}

[1] Morawska, L., \& Zhang, J., 2002, Combustion sources of particles. 1. Health relevance and source signatures, Chemosphere, 49, 1045-1058.

[2] Englert, N., 2004, Fine particles and human health - a review of epidemiological studies, Toxicology, 149, 235-242. 
[3] EPAQS, Airborne particles, Expert Panel on Air Quality Standards, London: HMSO, 2001.

[4] Harrison, R.M., 2004, Key pollutants - airborne particles, Science of the Total Environment, 334, 3-8.

[5] www.environment-agency.gov.uk

[6] www.europa.eu

[7] Bonnett, P.J.P., Appleby, P.G., \& Oldfield, F., 1998, Radionuclides in coastal and estuarine sediments from Wirral and Lancashire, Science of the Total Environment, 70,215-236.

[8] Clifton, J., McDonald, P., Plater, A., \& Oldfield, F., 1999, Derivation of a grain-size proxy to aid the modelling and prediction of radionuclide activity in saltmarshes and mud flats of the Eastern Irish Sea. Estuarine, Coastal and Shelf Science, 48, 511-518.

[9] Booth, C.A., Walden, J., Neal, A., \& Smith, J.P., 2005, Use of mineral magnetic concentration data as a particle size proxy: a case study using marine, estuarine and fluvial sediments in the Carmarthen Bay area, South Wales, UK Science of the Total Environment, 347, 241-253.

[10] Lewis, D., 2005, Southport Stories and Landscapes, Breedon Books Publishing Company Ltd., Derby, 156 pp.

[11] www.statistics.gov.uk

[12] www.sefton.gov.uk

[13] Xie, S., Dearing, J.A., \& Bloemandal, J., 2000, The organic matter content of street dust in Liverpool, UK and its association with dust magnetic properties. Atmospheric Environment, 34, 269-275.

[14] Shu, J., Dearing, J.A., Morse, A.P., Yu, L., \& Yuan, N., 2001, Determining the source of atmospheric particles in Shanghai, China, from magnetic geochemical properties. Atmospheric Environment, 35, 2615-2625.

[15] Oldfield, F., Richardson, N., Appleby, P.G., \& Yu, L., 1993, ${ }^{241}$ Am and ${ }^{137} \mathrm{Cs}$ activity in fine grained saltmarsh sediments from parts of the N.E. Irish Sea shoreline. Journal of Environmental Radioactivity, 19, 1-24.

[16] Zhang, W., Yu, L., \& Hutchinson, S.M., 2001, Diagenesis of magnetic minerals in the intertidal sediments of the Yangtze Estuary, China, and its environmental significance. Science of the Total Environment, 266, 160-175. 